Research Article

\title{
Forecasting of Global Market Prices of Major Financial Instruments
}

\author{
Roshani W. Divisekara, ${ }^{1}$ Ruwan D. Nawarathna, ${ }^{2}$ and Lakshika S. Nawarathna $\mathbb{D}^{2}$ \\ ${ }^{1}$ Postgraduate Institute of Science, University of Peradeniya, Peradeniya 20400, Sri Lanka \\ ${ }^{2}$ Department of Statistics and Computer Science, Faculty of Science, University of Peradeniya, Peradeniya 20400, Sri Lanka
}

Correspondence should be addressed to Lakshika S. Nawarathna; lakshikas@pdn.ac.lk

Received 23 July 2020; Revised 26 August 2020; Accepted 28 August 2020; Published 14 September 2020

Academic Editor: Aera Thavaneswaran

Copyright (C) 2020 Roshani W. Divisekara et al. This is an open access article distributed under the Creative Commons Attribution License, which permits unrestricted use, distribution, and reproduction in any medium, provided the original work is properly cited.

\begin{abstract}
One of the easiest and fastest ways of building a healthy financial future is investing in the global market. However, the prices of the global market are highly volatile due to the impact of economic crises. Therefore, future prediction and comparison lead traders to make the low-risk decisions with price. The present study is based on time series modelling to forecast the daily close price values of financial instruments in the global market. The forecasting models were tested with two sample sizes, namely, 5-year close price values for correlation analysis and 3-year close price values for model building from 2013 January to 2018 January. The forecasting capabilities were compared for both ARIMA and GARCH class models, namely, TGARCH, APARCH, and EGARCH. The bestfitting model was selected based on the minimum value of the Akaike information criterion (AIC) and Bayesian information criteria (BIC). Finally, the comparison was carried out between ARIMA and GARCH class models using the measurement of forecast errors, based on the Root Mean Square Deviation (RMSE), Mean Absolute Error (MAE), and Mean absolute percentage error (MAPE). The GARCH model was the best-fitted model for Australian Dollar, Feeder cattle, and Coffee. The APARCH model provides the best out-of-sample performance for Corn and Crude Oil. EGARCH and TGARCH were the better-fitted models for Gold and Treasury bond, respectively. GARCH class models were selected as the better models for forecasting than the ARIMA model for daily close price values in global financial market instruments.
\end{abstract}

\section{Introduction}

Recently, there are different methods for investing capital, for instance, investing in gold, investing in foreign currency, current savings, and fix deposits, when compared to the past [1]. In the past, a lot of people were interested to save money in commercial banks for making small interests [2].

In the modern world, lots of investors do not like to save capital in their savings accounts. They are interested in investing money in the global markets to get the maximum returns [2].

Investing in the global market is a simple and speedy method of building a stronger financial investment. The global economic markets are flattering increasingly systematic, and because of this, the competition between computable and traditional investors is warming up and developing modern research, models, and strategies to forecast asset prices. The consignments of knowledge accessible and computers greedy to analyze it are exceptional. Data, technology, and mathematics are now at the spearhead of a financial coup [1].

Presently, the mass investors worldwide started investing grand funds from their capitals. The motivation for investing in the global market is to gain return straightly. Thirty years ago, many companies worldwide mastered exceptional extension and invested mass funds from their capital. It is a durable outlay for companies and individuals. The number of listed companies in the global market has been increased continuously. The universal extension of the market prices and trade volume rates has been modified with hugely unstable oscillations [2]. 
Investment trading is dominated by several economic circumstances and components. These constituents are influenced by trading intramural and global trading. Sometimes, the market is unstable with enormous oscillations. Variation of the market variance over time is the volatility, and this changes from hugely high and low prices $[3,4]$.

The time series usage in volatile research in finance and econometrics is not limited to approximation matters, statistical abstractions, and pattern identification. Predominantly, portfolio selection, options trading, and risk management matters in trading have been sort out by these findings. Financial experts and business analysts are interested in taking solutions in an unpredictable situation, so they extremely center of attention to the volatility because it works as a debatable measurement. Recent trading markets are more comparable and desegregated because of globalization growth and technology evolution. The instruction encroachment from each market is strengthening as a result of these evolutions. Experimental works are activated in reactions to these expansions, and guidance communication implements were considered. The discoverers of that study path aimed at the returns sluice consequence between futures and its futures fundamental currency trades over trading's $[5,6]$.

Pattern recognition and predicting markets are commonly used in financial trading to estimate the futures market and commodity market. The major mission of financial predicting is to forecast the returns of trading benefits or prominent fluctuations. There are various methods to build models for factors that are affecting trading markets using historical data such as applying recent systems, combining statistical and mathematical hypotheses with economics, and materializing artificial-intelligence techniques. Besides, an association between the futures and futures fundamental currency trading was designated, and primary rates are mainly influenced by the futures prices. Moreover, experimental results illustrate the remarkable telesales relation with regards to pricing facts communication [1].

The motivation in this study is that, in the global market, the prices of instruments are highly fluctuating within a small period. So, uncertainty is high. Since there are uncertain unpredictable fluctuations, there is a high risk. Identifying the factors affecting price changes can predict the habits of price variations. The common computations for forecast cannot used to the global market forecasting because of uncertainty. These global market financial instruments have different returns. Therefore, it should fit separate forecasting models for each financial instrument. Identification of the future forecasts and their behavior can drive to the risk minimization.

The global market financial sector has 51 futures instruments in 8 main sectors. These main sectors are Currencies (CME), Agriculture (CBOT), Energies (NYMEX), Index, Metals, Interest Rates (CBOT), Softs (ICE), and Meats. The currencies sector has 10 futures instruments, the Agriculture sector has 8 futures instruments, the Energies sector has 8 futures instruments, the Index sector has 6 futures instruments, the Metals sector has 6 futures instruments, the Interest Rates sector has 5 futures instruments, the Softs sector has 5 futures instruments, and the Meat sector has 3 futures instruments.
The main motivation of this work is to forecast the global market prices of major financial instruments using Autoregressive Integrated Moving Average (ARIMA), Generalized Autoregressive Conditional Heteroscedasticity (GARCH), Threshold GARCH (TGARCH), Asymmetric Power ARCH (APARCH), and exponential GARCH (EGARCH) models and recognize the relationship between each market [7]. Here, we test the forecasting models with two sample sizes, namely, 5-year daily close price values for correlation analysis and 3-year daily close price values for model building for the past 5-year period from 2013 January to 2018 January. In the beginning, we test the correlations between these 51 major financial instruments to check their behaviors and their relationships. To check the correlations, we used daily close values for the 5-years period from 2013 January to 2018 January. After checking the relationships between markets, we select a few financial instruments and, then, move to build models to predict their futures.

Various types of statistical methods have been dominantly used to discuss the results. They are correlation analysis, descriptive statistical techniques, and time series analysis. These models will be used to build the model and to predict the future market properties. The best model was selected using the lowest AIC and BIC. Then, the out-ofsample, 30-day close price forecast was obtained and compared to the actual close price. Then, we calculate the error values for both ARIMA and GARCH family models. The best model will be identified using accuracy measures, namely, the Root Mean Square Error (RMSE), Mean Absolute Error (MAE), and Mean absolute percentage error (MAPE).

\section{Materials and Methods}

Historical daily close price values for 7 financial instruments extracted from TradeStation WebAPI (https://www. tradestation.com/platforms-and-tools/web-api/), which is a portal that enables the use of third-party trading applications to access TradeStation's real-time and historical market data, fast order-execution capabilities, and account and position information, were used in this study. The variables, symbols, and their related sectors are shown in Table 1. Open price, low price, high price, and close price were the four elements of the data. The close price reflects all the activities of the index on a trading day. Hence, the close price was chosen to represent the price of the index to predict.

First, the preliminary analysis was carried out to understand the patterns and trends of the data. Secondly, the graphical presentation was used to identify the distribution of the markets among each price value. 5-year daily close price values were used for correlation analysis, and 3-year daily close price values were used for model building for the past 5-year period from 2013 January to 2018 January. For one instrument, 1263 observations were used for correlation analysis and 595 observations were used for model building. The correlations between those 51 major financial instruments were tested to check their behaviors and their relationships. High correlations between instruments from the 
TABLE 1: Description of the variables used for the study.

\begin{tabular}{lcc}
\hline Symbol & Instrument & Sector \\
\hline AD & Australian Dollar & Currency \\
C & Corn & Agriculture \\
CL & Crude oil & Energies \\
ES & ES mini & Index \\
FC & Feeder cattle & Meats \\
GC & Gold & Metals \\
KC & Coffee & Softs \\
US & Treasury bond & Interest rates \\
\hline
\end{tabular}

same sectors have appeared. Therefore, one instrument was selected from each sector for further analysis. Then, ARIMA and GARCH models were fitted using past 3-year data, and 30-day future close price values were predicted using fitted models. The best model is identified using the minimum Akaike Information Criterion (AIC) value.

2.1. ARIMA Model. Time series data consists of two basics parts, namely, identifiable pattern, and random noise (error). There are different models in time series including autoregressive (AR), moving average (MA), autoregressive moving average (ARMA), and autoregressive integrated moving average (ARIMA). However, the most commonly used model is the Box-Jenkins ARIMA model that has been successfully applied in economic time series prediction [8]. Moreover, the seasonal time series data have seasonal ARIMA models which are also known as SARIMA. The $\operatorname{ARIMA}(p, d, q)$ model is given by the following equation:

$$
\left(1-\phi_{1} B-\cdots-\phi_{p} B^{p}\right)(1-B)^{d} Y_{t}=\delta+\left(1-\theta_{1} B-\cdots-\theta_{q} B^{q}\right) a_{t},
$$

where $\left(1-\phi_{1} B-\cdots-\phi_{p} B^{p}\right)$ is the AR operator of order $p$, $\left(1-\theta_{1} B-\cdots-\theta_{q} B^{q}\right)$ is the MA operator of order $q, \delta$ is the constant term, and $a_{t}$ is the shock element at time $t[9,10]$.

2.2. GARCH Model. The standardized residuals can be used for model checking. If the model fits well, the standardized residuals of the GARCH models that fitted to the residuals of ARIMA model data should be plotted. The GARCH model is known as a model of heteroscedasticity, which means it is not constant in variance. The GARCH model is written as the $\operatorname{GARCH}(q, p)$ model where $q$ is the number of moving average (MA) terms and $p$ is the number of autoregressive (AR) terms. The $\operatorname{GARCH}(q, p)$ model can be represented by the following equation:

$$
\begin{aligned}
& Z_{t}=\mu_{t}+\varepsilon_{t}, \quad \varepsilon_{t} \sim N\left(0, h_{t}\right), \\
& \varepsilon_{t}=e_{t} \sqrt{h_{t}}, \quad e_{t} \sim N(0,1), \\
& h_{t}=\propto+\sum_{i=1}^{p} \beta_{i} \varepsilon_{t-i}^{2}+\sum_{i=1}^{q} \gamma_{i} h_{t-i},
\end{aligned}
$$

where $\mu_{t}$ is the mean or constant term, $h_{t}$ is the conditional variance, $h_{t-i}$ is the past conditional variance, $\varepsilon_{t-i}^{2}$ is the past squared residual return, and $\propto>0, \beta_{i} \geq 0, \gamma_{i} \geq 0[11,12]$.
2.3. TGARCH Model. The threshold GARCH (TGARCH) model [13] is given by

$$
h_{t}^{1 / 2}=\omega+\sum_{i=1}^{p}\left(\alpha_{i} \epsilon_{t-i}^{+}+\gamma_{i}\left|\varepsilon_{t-i}^{-}\right|\right)+\sum_{j=1}^{q} \beta_{j} h_{t-j}^{1 / 2},
$$

where $\varepsilon^{+}=\max (\varepsilon, 0)$ and $\varepsilon^{-}=\min (\varepsilon, 0) . \alpha$ and $\gamma$ capture the positive and negative effects, respectively.

2.4. APARCH Model. The Asymmetric Power ARCH (APARCH) model [14] is as follows:

$$
h_{t}^{\partial / 2}=\omega+\sum_{i=1}^{p}\left(\alpha_{i}\left|\varepsilon_{t-i}\right|+\gamma_{i} \varepsilon_{t-i}\right)^{\partial}+\sum_{j=1}^{q} \beta_{j} h_{t-j}^{\partial / 2},
$$

where $\omega>0, \vartheta \geq 0, \quad \beta_{j} \geq 0, \quad(j=1,2, \ldots, q), \alpha_{i} \geq 0$, and $-1<\gamma_{i}<1, i=1, \ldots, p$. $\alpha$ and $\gamma$ recognize the good and bad effects.

2.5. EGARCH. Nelson [15] proposed that exponential GARCH (EGARCH) can be given as

$$
\ln \left(h_{t}\right)=\omega+\sum_{i=1}^{p} \alpha_{i}\left(\left|\frac{\varepsilon_{t-i}}{\sqrt{h_{t-i}}}\right|-\sqrt{\frac{2}{\pi}}\right)-\sum_{i=1}^{p} \gamma_{i}\left(\frac{\varepsilon_{t-i}}{\sqrt{h_{t-i}}}\right)+\sum_{j=1}^{q} \beta_{j} \ln \left(h_{t-j}\right) .
$$

The optimal forecasting model was formed by choosing the combination of the forecasting model's input parameters. Then, the 30-day close price forecast values were compared with the actual close price values. The error values for both models were calculated using the Root Mean Square Deviation (RMSE), Mean Absolute Error (MAE), and Mean Absolute Percentage Error (MAPE). The model which has the lowest MAPE and lowest RMSE values was selected as the best model out of these two models.

To find the best forecasting model for the data, a comparison between fitted ARIMA and GARCH family models was performed using the following steps:

(1) It is investigated whether the process is stationary and its variance does not change over time

(2) In case that the data were not stationary, they must be converted to stationary ones by taking the log or the difference transformation

(3) Then, the ACF, PACF, and EACF were checked for model identification

(4) Then, the best model was built, which has the lowest AIC

(5) Diagnostic checking for the best model was conducted by verifying the normality of the residuals using the QQ-norm plot and running the Ljung-Box tests [16]

(6) Finally, the results of the models (ARIMA and GARCH family) were compared through a criterion such as AIC and BIC, and the forecasting performance was tested using RMSE, MASE, and MAE criteria $[17,18]$ 
In summary, ARIMA and linear GARCH class models with three nonlinear GARCH family models, namely, TGARCH, APARCH, and TGARCH, were used to identify the model and forecast the daily close price values. The difference between forecasting GARCH family and ARIMA models was the behavior of the prediction intervals. In times of high volatility, prediction intervals using a GARCH class model widened to consider the higher amount of uncertainty. Similarly, the prediction intervals were narrow in times of lower volatility.

\section{Results and Discussion}

Figure 1 shows the global market sectors and their correlation groups. There is a strong correlation between the same sectors than the different markets. Therefore, for the analysis, one futures instrument from one financial sector was selected to get more accurate and unbiased results about the global market.

The normality test was applied for data mentioned in Table 1, and all variables were nonnormal. The daily close price data were taken for all financial instruments in the global market during the 3 years from 2015 January to 2018 January.

Table 2 shows the descriptive statistics of daily close price values for eight financial instruments from January 2015 to January 2018. The Minimum value, 1st Quartile, Median, Mean, 2nd Quartile, 3rd Quartile, and Maximum value were checked for selected 8 futures instruments. The contract sizes vary from those of financial instruments. Hence, the relationship between instruments cannot be compared.

According to the summary statistics in Table 2, the average daily close price for $\mathrm{AD}$ was 0.7463 , while the average daily close value for ES was 2195. Furthermore, the median daily close price value for CL was 54.57, while the median daily close price value for GC was 1296 .

3.1. Time Series Analysis. The time series plots of the time series of the daily closing price variables indicate that all values of the autocorrelation function are significantly far from zero and the trend's ACF is slowly decaying. This implies that there are strong correlations from past values. The stationarity of the time series should be verified. To obtain stationarity data, to remove correlations, and to obtain independent data, a transformation should be applied to the time series [19].

After taking the first differences in the time series of daily close price, the KPSS [20] test was performed. The $p$ value of the test was 0.1 , which is greater than the significance level of 0.05 . Hence, it can be rejected, and it can be concluded that the series is stationary.

3.2. Model Identification. The autocorrelation function (ACF) plot of the first differences for daily close price values was constructed for a variety of lags $k=1,2$, that is, among $(Y 1, Y 1+k),(Y 2, Y 2+k),(Y 3, Y 3+k), \ldots$, and $(Y n-k, Y n)$, which can identify the order of the ARMA model [21].

The ACF plot of the first difference of daily close price data values was measured for all $\mathrm{AD}, \mathrm{C}, \mathrm{CL}, \mathrm{ES}, \mathrm{FC}, \mathrm{GC}, \mathrm{KC}$, and the US. The trend of the plot was tail-off and cut-off at lag 1, which indicates that the ACF was MA (1).

The plot of the partial autocorrelation function (PACF) of the first difference of daily close price values for the global market estimated the correlation between $Y t$ and $Y t-k$ after removing the effect of the intervening variables $Y t-1, Y t-2$, $Y t-3, \ldots, Y t-k+1[21,22]$.

3.3. Determining the ARIMA Model Order. The trend of the PACF plot tends to cut off at lag 3 or lag 4 for AD and CL, which implies that the order or the parameters of the partial autocorrelation function were AR (4) or AR (4). The PACF plot tends to cut off at lag 2 or lag 3 for $\mathrm{C}$ and FC, which implies that the order or the parameters of the partial autocorrelation function were AR (2) or AR (3). The PACF plot tends to cut off at lag 5 or lag 7 for ES, which implies that the order of the parameters of the partial autocorrelation function were AR (5) or AR (7). The PACF plot tends to cut off at lag 2 or lag 4 for GC, which implies that the order or the parameters of the partial autocorrelation function were AR (2) or AR (4). The PACF plot tends to cut off at lag 3 or lag 11 for $\mathrm{KC}$, which implies that the order or the parameters of the partial autocorrelation function were AR (3) or AR (11), and finally, the PACF plot tends to cut off at lag 2 or lag 6 for US which implies that the order or the parameters of the partial autocorrelation function were AR (2) or AR (6). Mixed compounds of AR and MA models can be used to build many models. The composite models were initially acceptable according to the results of ACF and PACF plots; however, there were criteria to compare fitted models, in the prelude to choosing the best model.

The extended autocorrelation function (EACF) method [23] is an easy graphical tool to identify the orders of the ARMA model. The EACF method uses the fact that if the AR part of a mixed ARMA model is known, the output of the EACF is a two-way table, where the rows correspond to AR order $p$ and the columns to MA order $q$. Table 3 shows the AIC values of the selected ARIMA models for variables according to the ACF, PACF, and EACF method.

Table 3 exhibits the AIC values of suggested model variables. The best ARIMA model has the minimum value of AIC. Therefore, for AD, the ARIMA $(0,1,1)$ model, for $C$, the ARIMA $(0,1,1)$ model, for CL, the ARIMA $(0,1,2)$ model, for ES, the ARIMA $(1,1,1)$ model, for FC, the ARIMA $(0,1,1)$ model, for GC, the ARIMA $(0,1,1)$ model, for $\mathrm{KC}$, the ARIMA $(1,1,1)$ model, and for the US, the ARIMA $(0,1,1)$ model were selected. 


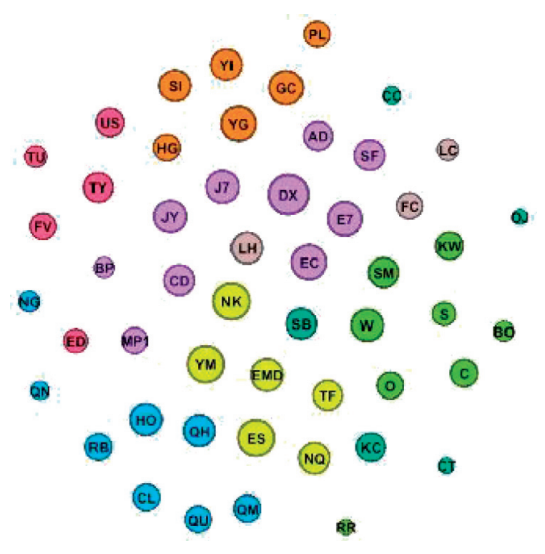

(a)

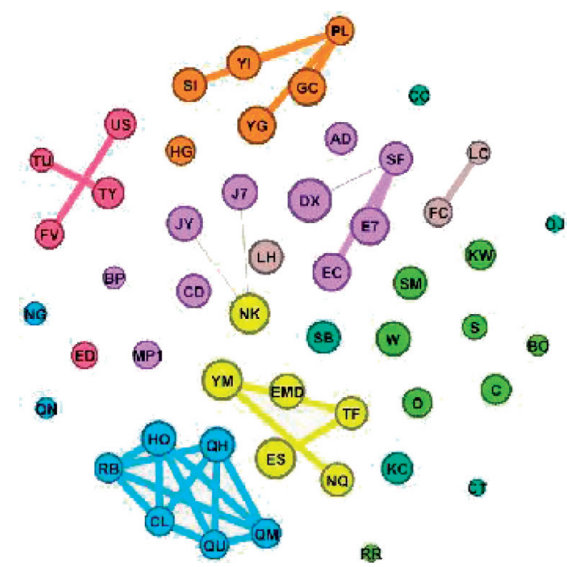

(c)

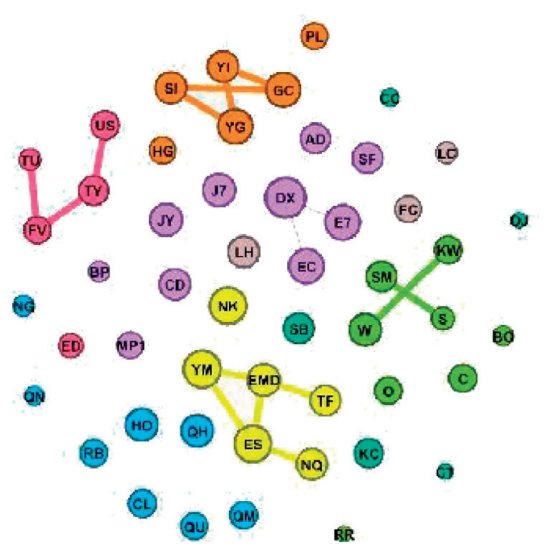

(b)

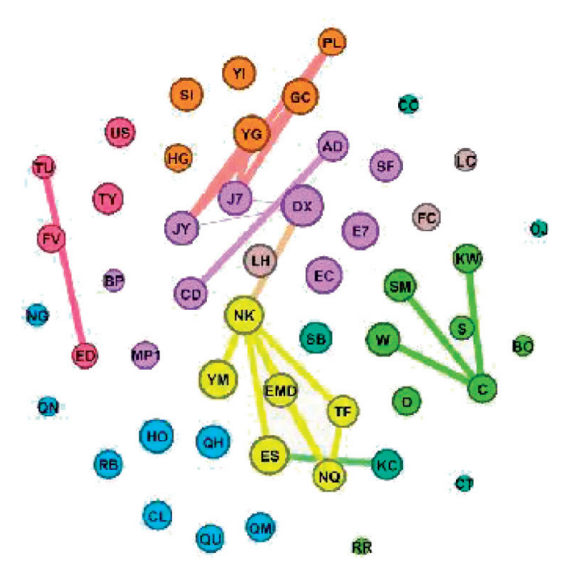

(d)

)

$$
\begin{aligned}
& \text { Currencies (CME) } \\
& \text { Agriculture (CBOT) } \\
& \text { Energies (NYMEX) } \\
& \text { Index }
\end{aligned}
$$

Figure 1: The global market sectors and correlation groups in the 2013-2017 daily close value. (a) All 51 futures instruments in the global market and the sectors belong to those instruments. (b) The highly correlated instruments group $(\sigma<-0.75$ and $0.75<\sigma)$. (c) The moderately correlated instruments group $(-0.75<\sigma<-0.5$ and $0.5<\sigma<0.75)$. (d) The low correlated group $(-0.5<\sigma<-0.25$ and $0.25<\sigma<0.5)$.

3.4. Model Estimation. Table 4 shows the estimated parameters for ARIMA models using the maximum likelihood method.

According to the parameter estimation results in Table 4, the MA parameter for AD was -0.0311 with 0.0417 standard error. The AR and MA parameters for CL were -0.0263 and -0.1298 , respectively.

3.5. Diagnostic Checking of the Best ARIMA Model. The next step was to conduct the diagnostic checking for the residuals of the ARIMA models. Model diagnostics were performed by testing the goodness of fit of a model. In this study, the selected ARIMA models were the best model from the suggested models. Therefore, the Box-Pierce and Ljung-Box tests were applied to determine the potential of the model in forecasting the global market's close price values.

Table 5 shows that the $p$ value is higher than 0.05 for all ARIMA models. Hence, it can be concluded that the autocorrelation is different from zero. Therefore, the selected models are appropriate. 
TABLE 2: Descriptive statistics of major financial instruments.

\begin{tabular}{|c|c|c|c|c|c|c|}
\hline Variable & Min & Q1 & Median & Mean & Q3 & Max \\
\hline $\mathrm{AD}$ & 0.6786 & 0.7249 & 0.7522 & 0.7463 & 0.7633 & 0.8048 \\
\hline $\mathrm{C}$ & 410.5 & 463.8 & 492.9 & 495.6 & 530.7 & 598.0 \\
\hline $\mathrm{CL}$ & 39.52 & 49.80 & 54.57 & 56.83 & 61.98 & 80.57 \\
\hline ES & 1814 & 2042 & 2104 & 2195 & 2383 & 2718 \\
\hline $\mathrm{FC}$ & 110.3 & 132.6 & 147.4 & 149.7 & 162.6 & 193.3 \\
\hline GC & 1123 & 1247 & 1296 & 1287 & 1330 & 1436 \\
\hline $\mathrm{KC}$ & 134.3 & 160.0 & 169.2 & 171.6 & 181.9 & 237.9 \\
\hline US & 130.9 & 141.6 & 146.0 & 146.4 & 150.3 & 164.8 \\
\hline
\end{tabular}

TABle 3: AIC values of suggested ARIMA models.

\begin{tabular}{|c|c|c|}
\hline Variable & Model & AIC \\
\hline \multirow{3}{*}{$A D$} & ARIMA $(3,1,1)$ & -4453.01 \\
\hline & ARIMA $(4,1,1)$ & -4452.11 \\
\hline & ARIMA $(0,1,1)$ & -4456.04 \\
\hline \multirow{3}{*}{ C } & ARIMA $(2,1,1)$ & 3737 \\
\hline & ARIMA $(3,1,1)$ & 3737.85 \\
\hline & ARIMA $(0,1,1)$ & 3734.41 \\
\hline \multirow{4}{*}{$C L$} & ARIMA $(3,1,1)$ & 1987.9 \\
\hline & ARIMA $(4,1,1)$ & 1989.6 \\
\hline & ARIMA $(0,1,2)$ & 1984.58 \\
\hline & ARIMA $(1,1,2)$ & 1985.91 \\
\hline \multirow{4}{*}{$E S$} & ARIMA $(5,1,1)$ & 5134.99 \\
\hline & $\operatorname{ARIMA}(7,1,1)$ & 5135.28 \\
\hline & ARIMA $(1,1,1)$ & 5130.34 \\
\hline & ARIMA $(2,1,1)$ & 5130.55 \\
\hline \multirow{4}{*}{$F C$} & ARIMA $(2,1,1)$ & 2694.63 \\
\hline & ARIMA $(3,1,1)$ & 2696.58 \\
\hline & ARIMA $(0,1,1)$ & 2691.71 \\
\hline & ARIMA $(2,1,1)$ & 2694.63 \\
\hline \multirow{4}{*}{$G C$} & ARIMA $(2,1,1)$ & 4631.41 \\
\hline & ARIMA $(4,1,1)$ & 4631.11 \\
\hline & ARIMA $(0,1,1)$ & 4629.98 \\
\hline & ARIMA $(2,1,2)$ & 4633.53 \\
\hline \multirow{3}{*}{$K C$} & ARIMA $(3,1,1)$ & 2920.22 \\
\hline & ARIMA $(1,1,1)$ & 2919.97 \\
\hline & ARIMA $(1,1,0)$ & 2918.05 \\
\hline \multirow{3}{*}{ US } & ARIMA $(2,1,1)$ & 1774.47 \\
\hline & ARIMA $(6,1,1)$ & 1781.38 \\
\hline & ARIMA $(0,1,1)$ & 1770.78 \\
\hline
\end{tabular}

3.6. Summary of Diagnostic Plots. The standardized residuals, the sample ACF of the residuals, and $p$ values for the Ljung-Box test statistic were used to check the assumption of independence of error terms. Randomized, nonpattern residuals implied independent errors. The residual plot, ACF, and PACF did not have any significant autocorrelation of any lag, which means that the ARIMA models were appropriated models for variables.

3.7. The Final Model. According to the parameter estimation results in Table 4, the final ARIMA models can be expressed as the following equations.

The final models were ARIMA $(0,1,1)$ for AD, C, FC, GC, and the US. This model can be expressed in the following form:
TABLE 4: Parameters estimation ML method for ARIMA models.

\begin{tabular}{lccc}
\hline Variable & Model & Parameter & SE \\
\hline$A D$ & ARIMA $(0,1,1)$ & $\Theta_{1}-0.0311$ & 0.0417 \\
\hline$C$ & ARIMA $(0,1,1)$ & $\Theta_{1}-0.0054$ & 0.0394 \\
\hline \multirow{2}{*}{$C L$} & ARIMA $(0,1,2)$ & $\Theta_{1}-0.0263$ & 0.0409 \\
& & $\Theta_{2}-0.1298$ & 0.0406 \\
\hline \multirow{2}{*}{$E S$} & \multirow{2}{*}{ ARIMA $(1,1,1)$} & $\Phi_{1} 0.6646$ & 0.1718 \\
& & $\Theta_{1}-0.7243$ & 0.1566 \\
\hline$G C$ & ARIMA $(0,1,1)$ & $\Theta_{1} 0.0830$ & 0.0427 \\
\hline \multirow{2}{*}{$K C$} & ARIMA $(0,1,1)$ & $\Theta_{1}-0.0138$ & 0.0388 \\
\hline$U S$ & \multirow{2}{*}{ ARIMA $(1,1,1)$} & $\Phi_{1} 0.3661$ & 0.7755 \\
\hline
\end{tabular}

TABle 5: Results of the Box-Pierce and Ljung-Box tests.

\begin{tabular}{lccc}
\hline Variable & $\chi^{2}$ & Df & $p$ value \\
\hline AD & 0.00019998 & 1 & 0.9887 \\
C & 0.0060869 & 1 & 0.9378 \\
CL & 0.017877 & 1 & 0.8936 \\
ES & 0.24851 & 1 & 0.6181 \\
FC & 0.0085805 & 1 & 0.9262 \\
GC & 0.00024216 & 1 & 0.9876 \\
KC & 0.05749 & 1 & 0.8105 \\
US & 0.00027009 & 1 & 0.9869 \\
\hline
\end{tabular}

$$
(1-B) y_{t}=\left(1+\theta_{1} B\right) e^{t}
$$

The final models were ARIMA $(1,1,1)$ for ES and KC. This model can be expressed as follows:

$$
\left(1-\phi_{1} B\right)(1-B) y_{t}=\left(1+\theta_{1} B\right) e^{t} \text {. }
$$

The final model was ARIMA $(0,1,2)$ for CL. This model can be expressed in the following form:

$$
\left(1-\phi_{2} B\right)\left(1-\phi_{1} B\right)(1-B) y_{t}=\left(1+\theta_{1} B\right) e^{t} .
$$

3.8. Forecasting. The main objective of building a model for a time series is forecasting the values for that series at future points of time. The best ARIMA models to represent the series for $\mathrm{AD}, \mathrm{C}, \mathrm{FC}, \mathrm{GC}$, and the US were ARIMA $(0,1,1)$, for ES and KC ARIMA $(1,1,1)$ and, finally, for CL ARIMA $(0,1,2)$.

Figure 2 shows the forecasts for 30 days of close price values for selected instruments. 30-day prediction values were plotted in the blue line, the $80 \%$ prediction interval was 


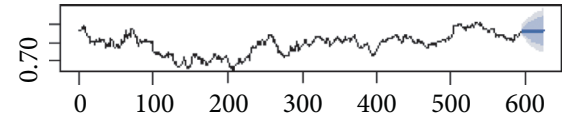

(a)

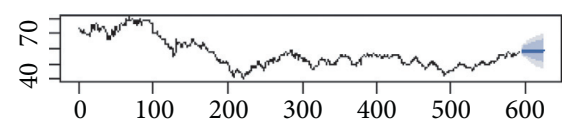

(c)

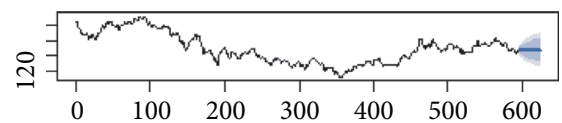

(e)

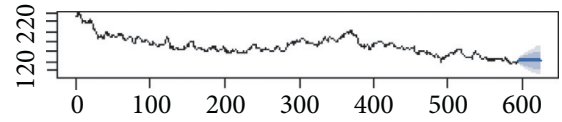

(g)

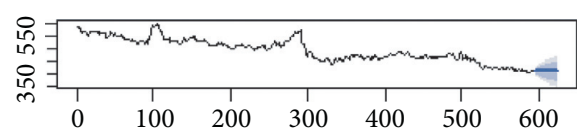

(b)

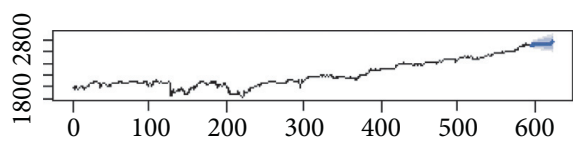

(d)

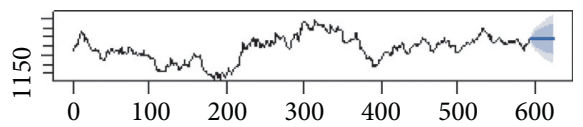

(f)

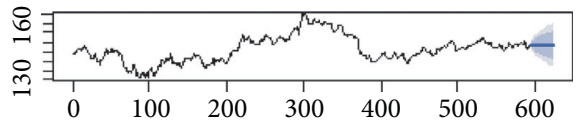

(h)

FIgURE 2: Forecast for 30 daily close price values. (a) Forecasts from ARIMA $(0,1,1)$ for AD. (b) Forecasts from ARIMA (0,1,1) for C. (c) Forecasts from ARIMA $(0,1,2)$ for CL. (d) Forecasts from ARIMA $(1,1,1)$ for ES. (e) Forecasts from ARIMA $(0,1,1)$ for FC. (f) Forecasts from ARIMA $(0,1,1)$ for GC. (g) Forecasts from ARIMA $(1,1,1)$ for KC. (h) Forecasts from ARIMA $(0,1,1)$ for US.

indicated in the dark gray color area, and the $95 \%$ prediction interval was shown in the light gray color area.

3.9. Model Identification. The time series was produced from a white noise series (residual of the ARIMA). Therefore, ACF plots could not be applied to select the orders $p$ and $q$ of the ARIMA model. Akaike Information Criteria (AIC) was used for various combinations of $p$ and $q$. Then, the model which had the minimum AIC was chosen as the best candidate model. EACF was guided to reduce the options of the best models.

Table 6 indicates the suggested GARCH models from EACF and AIC for variables. Final models were estimated using minimum AIC and BIC values. GARCH $(1,1)$ for AD, GARCH $(1,1)$ for C, GARCH $(1,2)$ for CL, GARCH $(1,2)$ for ES, GARCH $(1,1)$ for FC, GARCH $(3,4)$ for GC, GARCH $(1,1)$ for $\mathrm{KC}$, and $\mathrm{GARCH}(1,1)$ for the US were selected using minimum AIC and BIC values.

3.10. Lagrange Multiplier (ARCH-LM) Test. The test results presented in Table 7 reject the null hypothesis of no ARCH effect for daily close price values. The tests implied that there was significant volatility clustering in the residual series. Therefore, there was an ARCH effect in the series which indicates that the time series was heteroscedasticitic and volatile [24].

3.11. Parameter Estimation. Table 8 displays the results of the Box-Ljung test. The $p$ values indicated that the models are statistically significant.

The parameter estimation of GARCH models is displayed in Table 9. All the parameters were significant for AD, exclude $\beta 1$ nonsignificant value. Therefore, it was removed from the model. For $\mathrm{C}$, all the parameters were significant. For CL, $\beta 1$ and $\beta 2$ nonsignificant were removed from the
TABle 6: Suggested GARCH models from EACF and AIC for variables.

\begin{tabular}{|c|c|c|c|}
\hline Variable & Model & AIC & BIC \\
\hline \multirow{3}{*}{$A D$} & GARCH $(1,0)$ & -5.287483 & -5.257941 \\
\hline & GARCH $(1,1)$ & -5.287718 & -5.250792 \\
\hline & GARCH $(2,1)$ & -5.284379 & -5.240067 \\
\hline \multirow{3}{*}{$C$} & GARCH $(1,0)$ & 9.598306 & 9.627847 \\
\hline & GARCH $(1,1)$ & 9.582416 & 9.619342 \\
\hline & GARCH $(2,1)$ & 9.588508 & 9.632819 \\
\hline \multirow{3}{*}{$C L$} & GARCH $(1,2)$ & 6.152950 & 6.197262 \\
\hline & GARCH $(2,2)$ & 6.156085 & 6.207782 \\
\hline & GARCH $(3,2)$ & 6.161463 & 6.220546 \\
\hline \multirow{3}{*}{$E S$} & GARCH $(2,1)$ & 12.13357 & 12.17789 \\
\hline & GARCH $(1,2)$ & 12.13347 & 12.17778 \\
\hline & GARCH $(1,3)$ & 12.13857 & 12.19026 \\
\hline \multirow{3}{*}{$F C$} & GARCH $(1,0)$ & 7.936671 & 7.966212 \\
\hline & GARCH $(1,1)$ & 7.929158 & 7.966084 \\
\hline & GARCH $(2,1)$ & 7.933221 & 7.977533 \\
\hline \multirow{3}{*}{$G C$} & GARCH $(3,4)$ & 10.36803 & 10.44188 \\
\hline & GARCH $(6,4)$ & 10.38533 & 10.48134 \\
\hline & GARCH $(3,5)$ & 10.37408 & 10.45532 \\
\hline \multirow{3}{*}{$K C$} & GARCH $(1,0)$ & 7.673029 & 7.702570 \\
\hline & GARCH $(1,1)$ & 7.664752 & 7.701679 \\
\hline & GARCH $(2,1)$ & 7.675658 & 7.719969 \\
\hline \multirow{3}{*}{ US } & GARCH $(1,0)$ & 5.850009 & 5.879550 \\
\hline & GARCH $(1,1)$ & 5.846725 & 5.883651 \\
\hline & GARCH $(2,1)$ & 5.853085 & 5.897397 \\
\hline
\end{tabular}

model. For ES, $\beta 1$ and $\beta 1$ nonsignificant were removed from the model. For GC, $\alpha 2, \alpha 3, \beta 1, \beta 2, \beta 3$, and $\beta 4$ nonsignificant were removed from the model. For KC, $\beta 1$ nonsignificant was removed from the model. For the US, $\beta 1$ nonsignificant was removed from the model. 
TABLE 7: LM test for autoregressive conditional heteroscedasticity.

\begin{tabular}{lccc}
\hline Variable & Model & LM-ARCH & $p$ value \\
\hline AD & GARCH $(1,1)$ & 8.509965 & 0.7441175 \\
C & GARCH $(1,1)$ & 62.78456 & $<0.001$ \\
CL & GARCH $(1,2)$ & 12.72092 & 0.3896475 \\
ES & GARCH $(1,2)$ & 53.91283 & $<0.001$ \\
FC & GARCH $(1,1)$ & 50.21859 & $<0.001$ \\
GC & GARCH $(3,4)$ & 15.0366 & 0.2394412 \\
KC & GARCH $(1,1)$ & 17.25444 & 0.140274 \\
US & GARCH $(1,1)$ & 13.53744 & 0.3312158 \\
\hline
\end{tabular}

TABle 8: Box-Ljung test for GARCH models.

\begin{tabular}{lccc}
\hline Variable & Model & $\chi^{2}$ & $p$ value \\
\hline AD & GARCH $(1,1)$ & 2034 & $<0.001$ \\
C & GARCH $(1,1)$ & 2942.5 & $<0.001$ \\
CL & GARCH $(1,2)$ & 2814.2 & $<0.001$ \\
ES & GARCH $(1,2)$ & 2664.8 & $<0.001$ \\
FC & GARCH $(1,1)$ & 3801.4 & $<0.001$ \\
GC & GARCH $(3,4)$ & 2723.7 & $<0.001$ \\
KC & GARCH $(1,1)$ & 2936.2 & $<0.001$ \\
US & GARCH $(1,1)$ & 2936.2 & $<0.001$ \\
\hline
\end{tabular}

TABle 9: Parameter estimation of GARCH $(1,1)$.

\begin{tabular}{|c|c|c|c|c|}
\hline Variable & Model & Parameters & S.E. & $p$ value \\
\hline \multirow{4}{*}{$A D$} & \multirow{4}{*}{ GARCH $(1,1)$} & $\mu 7.553 e-01$ & $5.748 e-04$ & $<0.001$ \\
\hline & & $\alpha_{0} 1.893 e-05$ & $4.816 e-06$ & $<0.001$ \\
\hline & & $\alpha_{1} 1.000 e+00$ & $1.368 e-01$ & $<0.001$ \\
\hline & & $\beta_{1} 8.723 e-02$ & $1.025 e+00$ & 0.395 \\
\hline \multirow{4}{*}{ C } & \multirow{4}{*}{ GARCH $(1,1)$} & $\mu 470.35570$ & 0.57851 & $<0.001$ \\
\hline & & $\alpha_{0} 9.41034$ & 3.50690 & 0.00729 \\
\hline & & $\alpha_{1} 0.94295$ & 0.13596 & $<0.001$ \\
\hline & & $\beta_{1} 0.23805$ & 0.08988 & 0.00808 \\
\hline \multirow{5}{*}{$C L$} & \multirow{5}{*}{ GARCH $(1,2)$} & $\mu 51.25441$ & 0.23806 & $<0.001$ \\
\hline & & $\alpha_{0} 0.86055$ & 0.31380 & 0.0061 \\
\hline & & $\alpha_{1} 1.00000$ & 0.23861 & $<0.001$ \\
\hline & & $\beta_{1} 0.06070$ & 0.33109 & 0.8545 \\
\hline & & $\beta_{2} 0.05016$ & 0.16690 & 0.7638 \\
\hline \multirow{5}{*}{$E S$} & \multirow{5}{*}{ GARCH $(1,2)$} & $\mu 2.061 e+03$ & $1.844 e+00$ & $<0.001$ \\
\hline & & $\alpha_{0} 1.379 e+02$ & $3.458 e+01$ & $<0.001$ \\
\hline & & $\alpha_{1} 1.000 e+00$ & $1.332 e-01$ & $<0.001$ \\
\hline & & $\beta_{1} 1.290 e-01$ & $1.622 e-01$ & 0.426 \\
\hline & & $\beta_{2} 2.367 e-02$ & $9.275 e-02$ & 0.799 \\
\hline \multirow{4}{*}{$F C$} & \multirow{4}{*}{ GARCH $(1,1)$} & $\mu 146.1326$ & 0.3324 & $<0.001$ \\
\hline & & $\alpha_{0} 2.0045$ & 0.8187 & 0.0144 \\
\hline & & $\alpha_{1} 1.0000$ & 0.1376 & $<0.001$ \\
\hline & & $\beta_{1} 0.1315$ & 0.1103 & 0.2333 \\
\hline \multirow{9}{*}{$G C$} & \multirow{9}{*}{ GARCH $(3,4)$} & $\mu 1.310 e+03$ & $2.798 e+00$ & $<0.001$ \\
\hline & & $\alpha_{0} 9.636 e+01$ & $2.554 e+01$ & 0.000162 \\
\hline & & $\alpha_{1} 1.000 e+00$ & $1.319 e-01$ & $<0.001$ \\
\hline & & $\alpha_{2} 7.743 e-02$ & $1.384 e-01$ & 0.575965 \\
\hline & & $\alpha_{3} 1.000 e-08$ & $6531 e-02$ & 1.000000 \\
\hline & & $\beta_{1} 1.000 e-08$ & $8.419 e-02$ & 1.000000 \\
\hline & & $\beta_{2} 1.000 e-08$ & NA & NA \\
\hline & & $\beta_{3} 1.000 e-08$ & NA & NA \\
\hline & & $\beta_{4} 1.676 e-02$ & $2.036 e-02$ & 0.410364 \\
\hline \multirow{4}{*}{ KC } & \multirow{4}{*}{ GARCH $(1,1)$} & $\mu 166.6749$ & 0.4603 & $<0.001$ \\
\hline & & $\alpha_{0} 4.1971$ & 1.4602 & 0.00405 \\
\hline & & $\alpha_{1} 1.0000$ & 0.1371 & $<0.001$ \\
\hline & & $\beta_{1} 0.1475$ & 0.1025 & 0.15036 \\
\hline \multirow{4}{*}{ US } & \multirow{4}{*}{ GARCH $(1,1)$} & $\mu 146.2089$ & 0.3625 & $<0.001$ \\
\hline & & $\alpha_{0} 0.7346$ & 0.2514 & 0.00347 \\
\hline & & $\alpha_{1} 1.0000$ & 0.1761 & $<0.001$ \\
\hline & & $\beta_{1} 0.1274$ & 0.1403 & 0.36393 \\
\hline
\end{tabular}


TABLE 10: Comparison of forecast errors of ARIMA and GARCH models.

\begin{tabular}{|c|c|c|c|c|}
\hline Var & Model & RMSE & MAE & MAPE \\
\hline \multirow{5}{*}{$A D$} & ARIMA & 0.04212392 & 0.04095 & 0.051284 \\
\hline & GARCH & 0.0172119 & 0.0140733 & 0.017524 \\
\hline & TGARCH & 0.01727751 & 0.01415 & 0.01762 \\
\hline & APARCH & 0.0172308 & 0.0140967 & 0.017553 \\
\hline & EGARCH & 0.0173292 & 0.01421 & 0.017695 \\
\hline \multirow{5}{*}{$C$} & ARIMA & 51.75245 & 51.37237 & 0.122862 \\
\hline & GARCH & 8.127884 & 6.27 & 0.014797 \\
\hline & TGARCH & 4.837027 & 4.03 & 0.009562 \\
\hline & APARCH & 4.587574 & 3.86 & 0.009168 \\
\hline & EGARCH & 4.915537 & 4.08 & 0.009677 \\
\hline \multirow{5}{*}{$C L$} & ARIMA & 11.17219 & 10.99426 & 0.175763 \\
\hline & GARCH & 4.433551 & 3.954667 & 0.062562 \\
\hline & TGARCH & 3.809162 & 3.417 & 0.054092 \\
\hline & APARCH & 3.638178 & 3.283667 & 0.052027 \\
\hline & EGARCH & 3.736444 & 3.361333 & 0.05323 \\
\hline \multirow{5}{*}{ ES } & ARIMA & 34.4467 & 31.3007 & 0.257851 \\
\hline & GARCH & 22.56083 & 21.91637 & 0.023232 \\
\hline & TGARCH & 22.56083 & 21.91637 & 0.023232 \\
\hline & APARCH & 22.56083 & 21.91637 & 0.023232 \\
\hline & EGARCH & 22.56083 & 21.91637 & 0.023232 \\
\hline \multirow{5}{*}{$F C$} & ARIMA & 5.555951 & 4.9999 & 0.032833 \\
\hline & GARCH & 3.06689 & 2.6325 & 0.017276 \\
\hline & TGARCH & 3.687815 & 3.179167 & 0.020851 \\
\hline & APARCH & 3.086121 & 2.6525 & 0.017407 \\
\hline & EGARCH & 3.645199 & 3.145833 & 0.020634 \\
\hline \multirow{5}{*}{$G C$} & ARIMA & 59.91122 & 58.428 & 0.042608 \\
\hline & GARCH & 49.77807 & 47.07333 & 0.034301 \\
\hline & TGARCH & 41.07177 & 38.57333 & 0.028094 \\
\hline & APARCH & 40.27832 & 37.80667 & 0.027535 \\
\hline & EGARCH & 35.46411 & 32.87333 & 0.023931 \\
\hline \multirow{5}{*}{$K C$} & ARIMA & 27.52059 & 27.39157 & 0.197089 \\
\hline & GARCH & 3.875392 & 3.603333 & 0.026005 \\
\hline & TGARCH & 9.795952 & 8.923333 & 0.064539 \\
\hline & APARCH & 10.33573 & 9.393333 & 0.067943 \\
\hline & EGARCH & 4.665083 & 4.36 & 0.031484 \\
\hline \multirow{5}{*}{ US } & ARIMA & 5.048745 & 4.32146 & 0.030222 \\
\hline & GARCH & 4.201997 & 3.549167 & 0.024834 \\
\hline & TGARCH & 4.160593 & 3.515833 & 0.0246 \\
\hline & APARCH & 4.245958 & 3.589167 & 0.025113 \\
\hline & EGARCH & 4.184399 & 3.535833 & 0.024741 \\
\hline
\end{tabular}

3.12. Conditional Variance and Standardized Residuals. Some high values of residuals were recorded. Besides, the model was valid for volatility. The extreme value of the GARCH model was cleared (strong volatility). The increase of conditional variances has corresponded to the rise of volatility in the original series. The standardized residuals of the fitted model were larger values with respect to conditional variances and had a constant mean.

3.13. Model Diagnostics. To check the adequacy of a given time series model, it is common practice to test the significance of the residual autocorrelations. In the GARCH framework, this method is not relevant because the process is always white noise. However, to check the adequacy of a volatility model, the squared residual auto covariance should be invested.
Diagnostic of the adequacy of GARCH models was checked using the plot of the standardized squared residuals. Most values of ACF at successive lags were significantly close to zero which indicates that the models of GARCH were adequate [25].

The $p$ value of the Box-Ljung test exceeded 0.05. Therefore, the hypothesis in which the autocorrelation of residuals is different from 0 cannot be rejected, and it implied that the GARCH models were adequate. In Table 9 also, the $p$ value of coefficient(s) was significant compared to few that were not significantly greater than 0.05 .

3.14. Forecasting. The Ljung-Box statistics and corresponding $p$ values were obtained. That indicated no significant correlation at lags 10,15 , and 20 in a squared residual. The $p$ value was greater than 0.05 , and that implied the model adequately represents the residuals. 
TABLE 11: Next month average predictions using GARCH models.

\begin{tabular}{|c|c|c|c|c|c|c|c|c|}
\hline Model & $\mathrm{AD}$ & $\mathrm{C}$ & $\mathrm{CL}$ & ES & FS & GS & $\mathrm{KC}$ & US \\
\hline GARCH & 0.7826 & 413.800 & 58.294 & 2709 & 148.900 & 1321.367 & 142.100 & 148.153 \\
\hline TGARCH & 0.7826 & 417.427 & 59.002 & 2709 & 148.247 & 1329.867 & 147.687 & 148.120 \\
\hline APARCH & 0.7826 & 417.777 & 59.214 & 2709 & 148.880 & 1330.633 & 148.183 & 148.193 \\
\hline EGARCH & 0.7826 & 417.317 & 59.091 & 2709 & 148.287 & 1335.567 & 142.883 & 148.140 \\
\hline
\end{tabular}

3.15. Comparison between ARIMA and GARCH Class Models. The smaller value of the accuracy measurements of forecast errors, that were actual vs. predicted errors RMSE, MAE, and MAPE, were used in choosing the best model among ARIMA and GARCH class models, and results are shown in Table 10 .

Table 10 reports the results for an out-of-sample analysis of all models by comparing under three different criteria for four $\mathrm{GARCH}$ class models. For the $\mathrm{AD}, \mathrm{FC}$, and $\mathrm{KC}$ futures, the results support the use of the GARCH model. The APARCH model was the best fit model for the daily close price values of $\mathrm{C}$ and CL. The EGARCH and TGARCH were the appropriate models for the GC and US futures, respectively.

3.16. Future Predictions. Table 11 shows the next 30-day average prediction for daily close price values for financial instruments. The next 30-day average for $\mathrm{AD}$ was predicted as 0.755 .

\section{Conclusions}

Futures price values are fluctuating due to the impact of many factors. Hence, the traders are interested in forecasting futures price values to obtain optimum marketing decisions and to manage price risk. In this study, ARIMA and GARCH models were used to forecast daily close price values. GARCH models performed better than ARIMA models because of their ability to handle the volatility by the conditional variance. Therefore, the GARCH class models (TGARCH, APARCH, and EGARCH) were used to forecast the daily close price values. For the $\mathrm{AD}, \mathrm{FC}$, and $\mathrm{KC}$ futures, the results support the use of the GARCH model. The APARCH model was the best fit model for the daily close price values of $\mathrm{C}$ and CL. The EGARCH and TGARCH were the appropriate models for the GC and US futures, respectively.

\section{Data Availability}

Data are available from the authors upon reasonable request.

\section{Conflicts of Interest}

The authors declare that there are no conflicts of interest.

\section{Acknowledgments}

The authors are grateful to Mr. Chandika Jayawardane, Chief Analyst and Managing Director, Global Trade Finance and Quantitative Research, WISEWEL LLC, Kandy, Sri Lanka, for providing the data.

\section{References}

[1] R. F. O. H. Hausken and A. H. Ronold, "A dynamic ARMAGARCH model: forecasting returns and trading at the Oslo stock exchange," Master's thesis, Norwegian University of Science and Technology, Trondheim, Norway, 2018.

[2] R. M. K. T. Rathnayaka, D. M. K. N. Senevirathna, and S. C. Nagahawatta, "Empirical investigation of stock market behaviour in the colombo stock exchange," International Journal of Business, Economics and Management Works, vol. 1, no. 2, pp. 12-16, 2014.

[3] N. H. Miswan, N. A. Ngatiman, K. Hamzah, and Z. Z. Zamzamin, "Comparative performance of ARIMA and GARCH models in modelling and forecasting volatility of Malaysia market properties and shares," Applied Mathematical Sciences, vol. 8, no. 140, pp. 7001-7012, 2014.

[4] S. N. Kumari and A. Tan, "Modeling and forecasting volatility series: with reference to gold price," Thailand Statistician, vol. 16, no. 1, pp. 77-93, 2018.

[5] B. Bulut, "Forecasting the prices of non-ferrous metals with GARCH models \& volatility spillover from world Oil market to nonferrous metal markets," M.Sc. thesis, The Graduate School of Social Science of Middle East Technical University, Ankara, Turkey, 2010.

[6] S. Nadarajah, E. Afuecheta, and S. Chan, "GARCH modeling of five popular commodities," Empirical Economics, vol. 48, no. 4, pp. 1691-1712, 2014.

[7] S. Chand, S. Kamal, and I. Ali, "Modeling and volatility analysis of share prices using ARCH and GARCH models," World Applied Sciences Journal, vol. 19, no. 1, pp. 77-82, 2012.

[8] M. S. Helail, "A comparative study on ARIMA and GARCH models in forecasting time series data applied study on currency exchange data (ILS/JOR)," Master's thesis, Al-Azhar University-Gaza, Gaza City, State of Palestine, 2015.

[9] A. A. Adebiyi, A. O. Adewumi, and C. K. Ayo, "Stock price prediction using the ARIMA model," in Proceedings of the UKSim-AMSS 16th International Conference on Computer Modelling and Simulation, Cambridge, UK, March 2014.

[10] R. Shumway and D. Stoffer, "Time series analysis and its applications with R examples," Springer Texts in Statistics, Springer, Berlin, Germany, 3rd edition, 2010.

[11] R. Engle, "GARCH 101: the use of ARCH/GARCH models in applied econometrics," Journal of Economic Perspectives, vol. 15, no. 4, pp. 157-168, 2001.

[12] A. Bisht and A. Kumar, "Estimating volatility in prices of pulses in India: an application of GARCH model," Economic Affairs, vol. 64, no. 3, pp. 513-516, 2019.

[13] J.-M. Zakoian, "Threshold heteroskedastic models," Journal of Economic Dynamics and Control, vol. 18, no. 5, pp. 931-955, 1994.

[14] Z. Ding, C. W. J. Granger, and R. F. Engle, "A long memory property of stock market returns and a new model," Journal of Empirical Finance, vol. 1, no. 1, pp. 83-106, 1993.

[15] D. B. Nelson, "Conditional heteroskedasticity in asset returns: a new approach," Econometrica, vol. 59, no. 2, pp. 347-370, 1991. 
[16] C. Dritsaki, "The performance of hybrid ARIMA-GARCH modeling and forecasting oil price," International Journal of Energy Economics and Policy, vol. 8, no. 3, pp. 14-21, 2018.

[17] H. Lutkepohl and M. Kraetzig, Applied Time Series Econometrics, Cambridge University Press, Cambridge, UK, 2004.

[18] S. Suleiman, M. A. Alabi Issa, U. Usman, and U. Adamu, "Modeling and forecasting the crude oil price in Nigeria," International Journal of Novel Research in Marketing Management and Economics, vol. 2, no. 1, pp. 1-13, 2015.

[19] C. Uwilingiyimana, J. Munga'tu, and J. D. Harerimana, "Forecasting inflation in Kenya using ARIMA-GARCH models," International Journal of Management and Commerce Innovations, vol. 3, no. 2, pp. 15-27, 2016.

[20] D. Kwiatkowski, P. C. Phillips, P. Schmidt, and Y. Shin, "Testing the null hypothesis of stationarity against the alternative of a unit root," Journal of Econometrics, vol. 54, no. 1-3, pp. 159-178, 1992.

[21] V. Malik, "ARIMA/GARCH $(1,1)$ modelling and forecasting for a Ge stock prices using R," Asia Pacific Journals, vol. 8, no. 1, pp. 2349-2317, 2017.

[22] R. Adhikari and R. K. Agrawal, An Introductory Study on Time Series Modeling and Forecasting, LAP Lambert Academic Publishing, Saarbrücken, Germany, 2013.

[23] R. Tsay, Analysis of Financial Time Series, Wiley, Hoboken, NJ, USA, 2nd edition, 2005.

[24] C. Francq and J. Zakol̈an, GARCH Models Structure, Statistical Inference and Financial Applications, Wiley, Hoboken, NJ, USA, 1st edition, 2019.

[25] F. Iqbal, "Diagnostic test for GARCH models based on absolute residual autocorrelations," Pakistan Journal of Statistics and Operation Research, vol. 9, no. 2, pp. 171-180, 2013. 